This is a post-peer-review, pre-copyedit version of an article published in Current Opinion in Plant Biology. The final authenticated version is available online at: https://doi.org/10.1016/j.pbi.2015.11.004

\title{
Genetic and hormonal control of vascular tissue proliferation
}

Wouter Smet ${ }^{1}$ and Bert De Rybel ${ }^{1,2,3}$

${ }^{1}$ Laboratory of Biochemistry, Wageningen University, Dreijenlaan 3, 6703HA Wageningen, the Netherlands

${ }^{2}$ Department of Plant Systems Biology, VIB, Technologiepark 927, B-9052 Ghent, Belgium

${ }^{3}$ Department of Plant Biotechnology and Bioinformatics, Ghent University, Technologiepark 927, B-9052 Ghent, Belgium

Corresponding author: Bert De Rybel (ㄹeryb@psb.vib-ugent.be)

WS: wouter.smet@wur.nl

BDR: beryb@psb.vib-ugent.be

\begin{abstract}
The plant vascular system develops from a handful of provascular initial cells in the early embryo into a whole range of different cell types in the mature plant. In order to account for such proliferation and to generate this kind of diversity, vascular tissue development relies on a large number of highly oriented cell divisions. Different hormonal and genetic pathways have been implicated in this process and several of these have been recently interconnected. Nevertheless, how such networks control the actual division plane orientation and how they interact with the generic cell cycle machinery to coordinate these divisions remains a major unanswered question.
\end{abstract}




\section{Introduction}

Vascular tissues form an efficient fluid conducting system that stretches throughout the entire plant body. Besides providing long-distance transport of water, sugars, nutrients, hormones and other signaling molecules, it also contributes to mechanical support. Broadly speaking, the vascular system consists of three major tissue types: xylem, phloem and (pro)cambium cells (Figure 1). Based on ontogeny and anatomical studies during embryogenesis and in the primary root meristem, it seems that all vascular cell types are derived from procambium cell divisions [1-4]. Although the organization of vascular tissues differs tremendously between species, within different organs and even depending on the developmental stage, procambium is in general located between xylem and phloem cell types (Figure 1). Xylem tissues differentiate into several cell types including tracheary elements, xylem fibers and xylem parenchyma cells. Each of these xylem cell types contain distinct lignified secondary walls that combine the required mechanical strength with connectivity between cells $[5,6]$. Phloem on the other hand, consists of sieve elements, companion cells, phloem fibers and phloem parenchyma cells. Intriguingly, the different vascular cell types described above all originate from only a few procambium initial cells in the early embryo. Unlike for example epidermis and cortex, procambium cells thus need to develop into a vast array of cell identities; a process that is dependent on specific oriented cell divisions.

In the following, we will illustrate how these oriented cell divisions are critically involved in developing an efficient vascular system and we will highlight how genetic and hormonal regulatory networks control vascular proliferation. Because most of these interaction networks have been best described in Arabidopsis thaliana, we will focus on this model species. For a more comprehensive overview of the different vascular cell types and their function, we refer to some excellent recent reviews [7-11].

\section{Oriented cell divisions shape the vascular cell lineage}

Because plant cells have rigid cell walls and are immobilized within a tissue context, cell expansion and oriented cell divisions are the main mechanisms to shape a three-dimensional organ and eventually the entire plant body. Two basic types of divisions occur in plants: perpendicular (anticlinal) and parallel (periclinal) to the surface of the plant (Figure 1). An 
anticlinal cell division (AD) adds a new cell to an existing cell file and is thus the main driver of longitudinal growth along the main body axis of the plant. A periclinal cell division (PD) however provides an increase in the number of cell-files and thus control radial growth. These divisions often result in daughter cells of different size or identity and are therefore also referred to as 'formative divisions'[12]. The existence of these clearly distinct division types also suggests that control mechanisms must be present to specifically position the division plane and control its orientation. This process plays vital roles throughout plant development, starting with the very first division of the zygote [13,14]. Later during embryogenesis, specific anticlinal and periclinal cell divisions generate all major tissue types of the plant $[1,2]$. Post-embryonically, cell division orientations have also been shown to be of vital importance in e.g. root stem cells [15], stomatal development [16] and lateral root formation $[17,18]$.

Although a tight control of cell division orientation is important throughout plant development, this is specifically true for vascular tissues. During the early globular stage of embryogenesis, four procambium cells expressing early vascular marker genes [19] will undergo a series of PDs giving rise to a fully patterned vascular bundle containing about 25 cell files (excluding pericycle cells) in a mature embryonic root (Figure 1). In Arabidopsis, the young root vasculature is organized in a bisymmetric pattern with a central one-cell wide xylem axis, flanked by two phloem poles and separated by procambium. Additional rounds of post-embryonic PDs in the meristematic vascular tissues will further increase the number of vascular cell files from 25 just above the quiescent center to about 30 in the elongation zone (Figure 1). Of particular interest in this case is the phloem cell lineage. Here, a single procambium cell undergoes a PD resulting in another procambium cell and a sieve element precursor cell. The latter undergoes another round of PD, generating a proto- and a metaphloem cell file (Figure 1). Two more PD events generate the companion cell files on each side of the sieve element cell files from neighboring procambium cells [20,21].

Later in development during secondary growth, subsets of procambium cells will develop into vascular cambium; a meristem responsible for the secondary radial growth of stem and root tissues (Figure 1). During secondary growth, PDs are responsible for the dramatic increase in size of the vascular bundle. The organization of the root vascular tissues also changes during this process in which xylem proliferates in the center, phloem at the periphery and cambium in the middle [11]. In the stem, cambium in the vascular bundles is first connected via 
interfascicular cambium that will then generate more phloem and xylem cells [8]; resulting in an organization similar to that of the mature root (Figure 1).

\section{Genetic and hormonal control mechanisms}

Over the past few years, our understanding of the hormonal and genetic control mechanisms of vascular development has increased tremendously. Genetic players ranging from early embryogenesis to late differentiation are now identified. However, despite the importance of oriented cell divisions for the vascular cell lineage, only a few pathways have been implicated in this process so far. Here, we will briefly discuss these pathways that act during primary and secondary growth and highlight how these interact in controlling vascular proliferation.

A major pathway controlling vascular PDs acts during early embryogenesis and also at least in the post-embryonic root. The auxin dependent bHLH transcription factor TARGET OF MONOPTEROS5 (TMO5) is first expressed in the four procambium cells during early globular stage of embryogenesis [22]. TMO5 and its closest homologs form heterodimer complexes with another bHLH transcription factor called LONESOME HIGHWAY (LHW) and its respective homologs [23,24] (Figure 2). Loss-of-function of TMO5 or LHW clade members results in strongly reduced vascular cell file numbers, whereas ectopic expression of both TMO5 and LHW is able to ubiquitously induce PDs in the root $[23,25,26]$. Intriguingly, the expression of both bHLH transcription factors overlaps in young xylem cells while the PDs mostly take place in the neighboring procambium cells, suggesting that a mobile signal acts downstream [23]. The cytokinin (CK) biosynthetic gene LONELY GUY4 (LOG4) and its close homolog LOG3 were identified as direct targets of the TMO5/LHW dimer complex $[3,27]$. CK is a good candidate to act as this mobile signal because CK-signaling is clearly required for PD. This is reflected by the fact that mutants in the biosynthetic pathway (e.g. $\log 1,2,3,5,6,7,8[28,29])$, perception by the CK receptors (e.g. wooden leg [20]) and mutants in downstream signaling events (e.g. arr1,10,12 [30,31]) all show strongly reduced PDs in the vascular bundle. In all these mutants, patterning within the vascular bundle is also disturbed, indicating that cell division orientation and patterning events are tightly linked. Although TMO5/LHW-dependent CK production along the xylem axis is able to trigger PDs in neighboring procambium cells, it seems unlikely that this pathway also controls the high number of PDs in the more distantly positioned phloem cell lineage, suggesting the existence of a yet unidentified factor controlling phloem cell proliferation. 
The TMO5-LHW dimer was very recently linked to another pathway controlling PD through the ACAULIS5/THICKVEIN (ACL5/TKV) gene [32-34]. Loss of ACL5 function causes vascular cell proliferation in combination with increased xylem cell differentiation $[35,36]$. The polyamine thermospermine produced by ACL5 has been shown to repress the translational inhibitory effect of the up-stream open reading frames (uORFs) located in the 5' leader sequence of several genes, including SUPRESSOR OF ACAULIS51 (SAC51) and the closely related SAC51-LIKE (SACL) genes. These encode yet another clade of bHLH transcription factors [35], which also form heterodimer complexes with LHW [23,24,37,38]. This way, SACL proteins compete with TMO5 for the LHW binding partner, reducing the amount of active TMO5-LHW [37,38]. As ACL5 and SACL genes themselves are downstream targets of TMO5-LHW, these factors constitute a negative feedback loop that controls TMO5LHW activity at the post-translational level [37,38]. Intriguingly, TMO5-LHW overexpression shows vascular differentiation phenotypes similar to the acl5 mutant [37]. This suggests that the TMO5-LHW pathway might control both vascular proliferation and differentiation processes [37,38].

Furthermore, ACL5 is under transcriptional control of both MP and the auxin-dependent homeodomain - leucine zipper (HD-ZIPIII) protein ARABIDOPSIS THALIANA HOMEOBOX 8 (ATHB8) [39-41] (Figure 2). Strikingly similar to TMO5-LHW misexpression and the acl5 mutant, loss-of-function of HD-ZIPIII genes show increased vascular PDs in the hypocotyl and root. Increased HD-ZIPIII levels however, show strongly reduced root vascular cell numbers $[42,43]$, analogous to tmo5 or lhw higher order mutants [23] or SACL overexpression [37,38]. It will be interesting to see if the HD-ZIPIII family members will be linked further to TMO5-LHW, or whether they operate in parallel.

In conclusion, the pathways that control primary vascular tissue growth are slowly being linked. These are the first steps towards a full understanding of the integrated transcriptional network controlling vascular proliferation.

Later in development during secondary growth, PDs in the hypocotyl and stem are controlled by the CLE41/44 or TRACHEARY ELEMENT DIFFERENTIATION INHIBITORY FACTOR (TDIF) peptide and its PHLOEM INTERCALATED WITH XYLEM / TDIF RECEPTOR (PXY/TDR) receptor [44-46] (Figure 2). This CLE-type peptide, produced in the secondary phloem, travels to the cambium where it binds the PXY/TDR receptor and induces the expression of the WUSCHEL-RELATED HOMEOBOX4 (WOX4) and WOX14 transcription factors [44-48]. Mutants in these factors all show reduced numbers of vascular 
cell files, indicating a key role during lateral growth both in Arabidopsis and poplar [48]. Moreover, WOX4 and WOX14 act redundantly in controlling the number of vascular cell files within the cambium as the wox4/wox 14 double mutant shows a further reduction in cell files compared to the wox4 single mutant $[47,49]$. This regulatory pathway is also profoundly controlled by hormonal input. For example, similar to primary vascular proliferation, $\mathrm{CK}$ is required for secondary growth, as procambium divisions are absent in a CK biosynthesis mutant and can be reinstalled by CK treatments [50]. Also, WOX4 was shown to be auxinresponsive in a PXY/TDIF independent manner, while ETHYLENE RESPONSE FACTORs $(E R F s)$ are upregulated in the stem and hypocotyl of the pxy/tdr and wox4 single mutants. Additionally, the pxy erf109 erf018 triple mutant shows a reduction of vascular cell files within the hypocotyl [51].

Intriguingly, the networks controlling vascular proliferation during primary and secondary growth are clearly distinct with no overlaps or interactions uncovered so far. It remains to be seen if this is truly the case, or whether it reflects a more historical perspective in the sense that research into these processes has focused on specific pathways. Despite this consideration, the genetic and hormonal pathways discussed above all seem to control vascular proliferation. However, it remains entirely unclear how they exert their effect on the actual orientation of cell divisions in the vascular tissues. Indeed, there appears to be a gap in our understanding of how these regulatory networks are linked to cell division plane orientation.

\section{Bridging the gap}

A large number of proteins are required to correctly execute oriented cell divisions. Many of these affect actin or microtubule (MT) dynamics and organization during different stages of cell division, while others determine a plasma membrane domain where the cell plate will fuse at the end of cytokinesis [52-66]. In all cases, mutations do not cause a 90-degree rotation of the cell division plane, but result in randomly oriented cell divisions. Hence, these factors do not control the exact switching of the division plane between anticlinal or periclinal divisions, but are rather part of the canonical cell division machinery itself.

Nevertheless, as the preprophase band (PPB) normally forms in the same orientation as the cortical cytoskeletal organization [67], the switch in cell division orientation required to 
generate a PD should be preceded by a similar 90-degree rotation of the cortical MT array from transverse to longitudinal. This type of cytoskeletal rotation can be induced by light stimulus in hypocotyl epidermis cells through KATANIN-dependent MT severing and plusend polymerization [68] and TONNEAU2/FASS-dependent branching nucleation [69]. Similarly, short-term auxin treatments [70] also provoke similar interphase MT reorientations, although an opposite reorientation from longitudinal to transverse by auxin and auxin in combination with gibberellic acid treatments has also been reported [71]. Besides hormones, sensing physical pressure is also able to switch the orientation of cortical MT [72-75]. It is however not straightforward to imagine how cells in the vascular system would feel differential pressure, or how light could induce the required MT reorientation in root vascular cells. Despite these considerations, KATANIN and TONNEAU2/FASS are good molecular targets to act downstream of the genetic pathways we have described previously. Other candidates present in root vascular cells are AURORA kinases. Especially during lateral root development in aur1-2 aur2-2 double mutants, the highly elongated pericycle cells frequently undergo PD, instead of the normal AD [76]. In contrast, a switch from PD to AD has been observed in loss-of-function mutant embryos of TORMOZ (TOZ) [77]. The TOZ gene encodes a nucleolar protein with WD40 repeats but its precise function remains unknown. It is conceivable that some or all of these molecular players will eventually be found as common downstream targets of the genetic pathways regulating vascular proliferation described above.

\section{Future perspectives}

In order to form functional vascular tissues, specifically oriented cell divisions have to occur in the correct cell at the right time, suggesting that this is a highly coordinated developmental process. Several genetic and hormonal pathways controlling vascular proliferation have been identified over the past years. A major future challenge will be to determine if these pathways independently provide cues for vascular proliferation or whether they all interconnect to control common target genes.

Another poorly explored level of regulation involves the spatial and temporal resolution. Although we know that several key factors are expressed in vascular tissues throughout plant development, most published information is limited to a specific developmental context. Therefore, a second challenge will be to evaluate if these factors act during other stages of development and in different parts of the plant. 
Finally, it remains entirely unknown what might act downstream of these genetic factors to control the actual orientation of cell divisions in the vascular tissues. Whatever the identity of these downstream regulators might be, it is very likely that they will eventually control MT orientation and/or subsequent PPB positioning. Future work will have to show if such factors can be identified in vascular tissues or if for example cell polarity plays an important role; similar to stomatal development $[78,79]$. Finally, it remains possible that control of oriented cell divisions occurs through non-genetic determinants such as mechanical stress and light; or a combination of all these factors. 


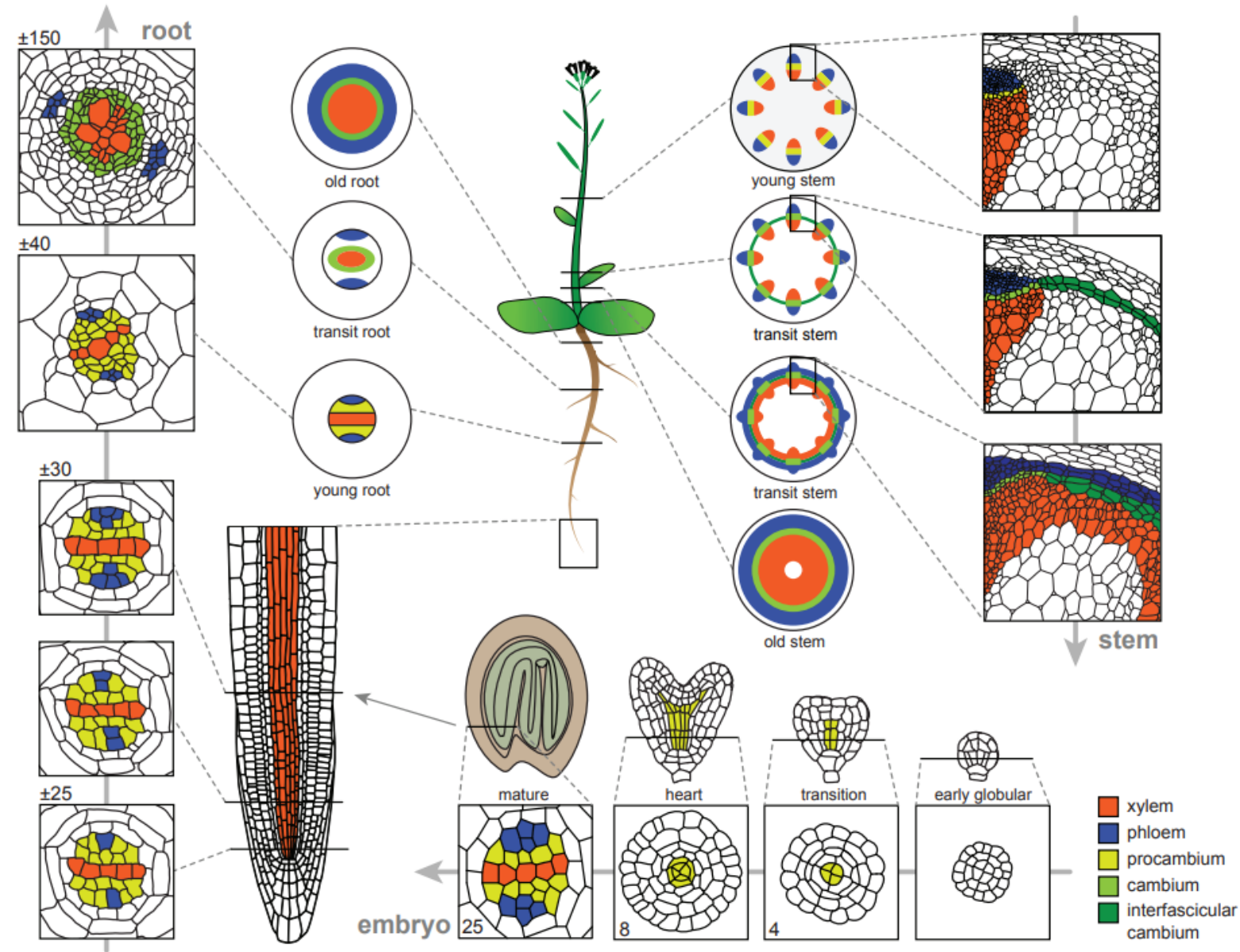

Figure 1: An overview of how periclinal cell divisions contribute to shaping the vascular cell lineage throughout plant development. Starting from only four procambium cells in the early embryo (bottom panel) periclinal divisions increase the number of vascular cell files both in root (left panel) and in stems (right panel). The vascular tissues of the shoot and root lateral organs are omitted for simplicity. The location of each cross section is indicated on a young Arabidopsis thaliana plant in the middle. The representative location of the section through the mature embryo in comparison to the post-embryonic root meristem is indicated with a thin arrow. The large gray arrows behind the cross sections represent the time axis during development and the numbers on or next to the cross sections represents the number of cells within the vasculature (excluding the pericycle cells). Note that two of the four procambium cells in the early globular stage embryo share a common cell wall, predicting the future xylem axis. 


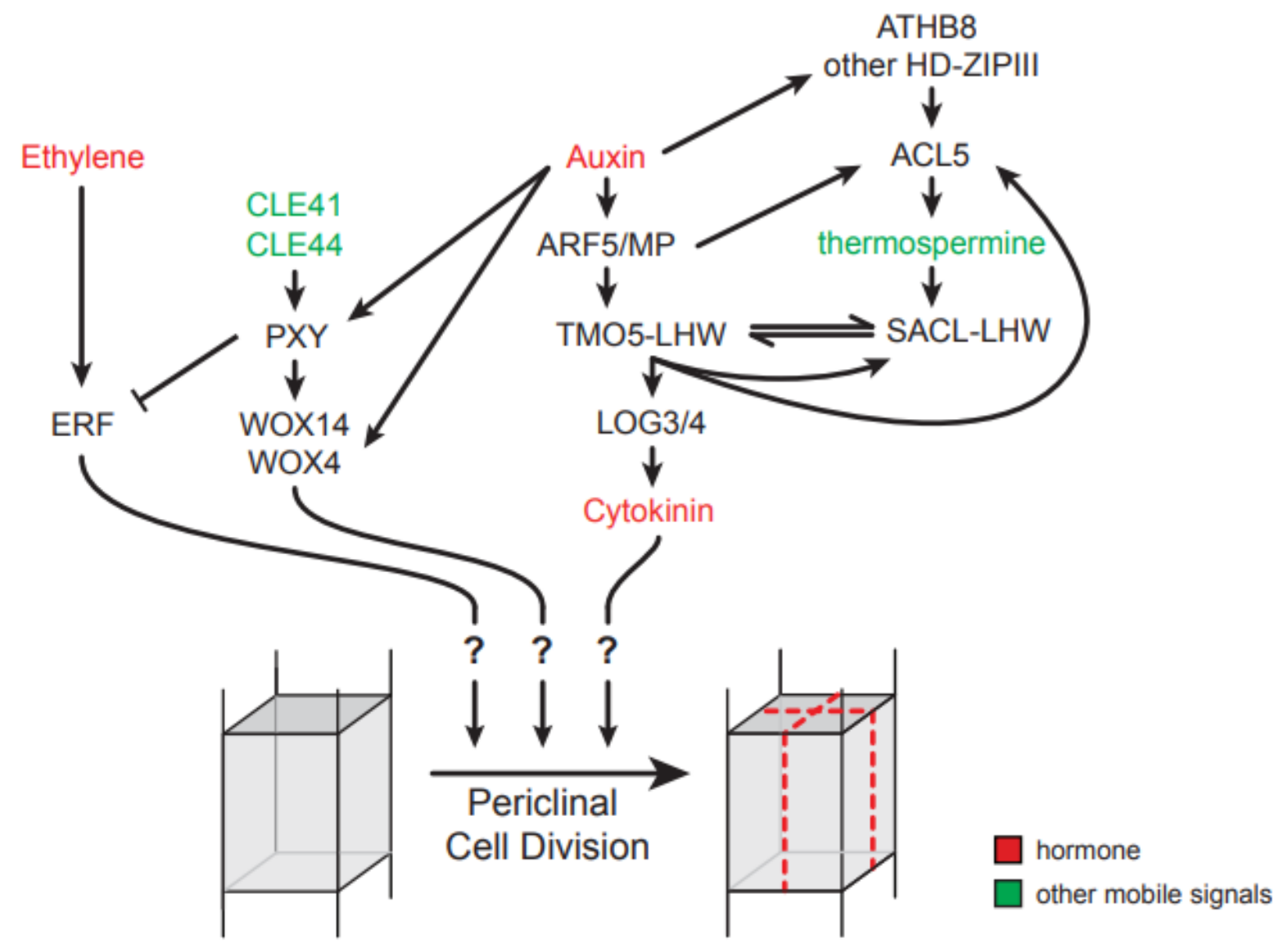

Figure 2: Schematic representation of the known hormonal and genetic pathways controlling vascular proliferation. Several pathways acting in different tissues during distinct developmental stages have been implicated in vascular proliferation (hormonal inputs to this network are highlighted in red, other mobile signals in green). The double arrow indicates competition for LHW in both heterodimer complexes. It remains unclear if these pathways control the same downstream target genes or whether they independently provide cues for cell division orientation. The downstream factors controlling the actual orientation of cell divisions remain unknown.

\section{Acknowledgements}

The authors would like to thank Ondřej Smetana (Mähönen lab, Helsinki, Finland) and EvaMaria Sehr (Greb lab, Heidelberg, Germany) for contributing to images of secondary growth in roots and stems respectively. We are grateful to Daniel Van Damme, Tom Beeckman and Dolf Weijers for critical reading of the manuscript. This work was funded by the Netherlands Organisation for Scientific Research (NWO; VIDI 864.13.001) and by The Research Foundation - Flanders (FWO; Odysseus II G0D0515N and Post-doc grant 12D1815N). 


\section{References}

1. Scheres B, Dilaurenzio L, Willemsen V, Hauser MT, Janmaat K, Weisbeek P, Benfey PN: Mutations Affecting the Radial Organization of the Arabidopsis Root Display Specific Defects Throughout the Embryonic Axis. Development 1995, 121:53-62.

2. Scheres B, Wolkenfelt H, Willemsen V, Terlouw M, Lawson E, Dean C, Weisbeek P:

Embryonic Origin of the Arabidopsis Primary Root and Root-Meristem Initials. Development 1994, 120:2475-2487.

3. De Rybel B, Adibi M, Breda AS, Wendrich JR, Smit ME, Novák O, Yamaguchi N, Yoshida S, Van Isterdael G, Palovaara J, et al.: Plant development. Integration of growth and patterning during vascular tissue formation in Arabidopsis. Science 2014, 345:1255215.

4. Yoshida S, Barbier de Reuille P, Lane B, Bassel GW, Prusinkiewicz P, Smith RS, Weijers D: Genetic control of plant development by overriding a geometric division rule. Dev Cell 2014, 29:75-87.

5. Oda Y, Fukuda H: Secondary cell wall patterning during xylem differentiation. Curr Opin Plant Biol 2012, 15:38-44.

6. Mauseth J: Plant anatomy. Benjamin/Cummings Publ.CO 1988.

7. Furuta KM, Hellmann E, Helariutta Y: Molecular control of cell specification and cell differentiation during procambial development. Annu Rev Plant Biol 2014, 65:607638.

8. Jouannet V, Brackmann K, Greb T: (Pro)cambium formation and proliferation: two sides of the same coin? Curr Opin Plant Biol 2015, 23:54-60.

9. Lucas WJ, Groover A, Lichtenberger R, Furuta K, Yadav SR, Helariutta Y, He XQ, Fukuda H, Kang J, Brady SM, et al.: The Plant Vascular System: Evolution, Development and Functions. Journal of Integrative Plant Biology 2013, 55:294-388.

10. Růžička K, Ursache R, Hejátko J, Helariutta Y: Xylem development - from the cradle to the grave. New Phytol 2015.

11. Nieminen K, Blomster T, Helariutta Y, Mähönen AP: Vascular Cambium Development. Arabidopsis Book 2015, 13:e0177.

12. De Smet I, Beeckman T: Asymmetric cell division in land plants and algae: the driving force for differentiation. Nat Rev Mol Cell Biol 2011, 12:177-188.

13. van Dop M, Liao CY, Weijers D: Control of oriented cell division in the Arabidopsis embryo. Curr Opin Plant Biol 2015, 23:25-30. 
14. Ueda M, Laux T: The origin of the plant body axis. Curr Opin Plant Biol 2012, 15:578584.

15. Bennett T, Scheres B: Root Development-Two Meristems for the Price of One? Plant Development 2010, 91:67-102.

16. Lau OS, Bergmann DC: Stomatal development: a plant's perspective on cell polarity, cell fate transitions and intercellular communication. Development 2012, 139:3683-3692.

17. Lavenus J, Goh T, Roberts I, Guyomarc'h S, Lucas M, De Smet I, Fukaki H, Beeckman T, Bennett M, Laplaze L: Lateral root development in Arabidopsis: fifty shades of auxin. Trends Plant Sci 2013, 18:450-458.

18. Péret B, Larrieu A, Bennett MJ: Lateral root emergence: a difficult birth. $J$ Exp Bot 2009, 60:3637-3643.

19. De Rybel B, Breda AS, Weijers D: Prenatal plumbing--vascular tissue formation in the plant embryo. Physiol Plant 2014, 151:126-133.

20. Mähönen AP, Bonke M, Kauppinen L, Riikonen M, Benfey PN, Helariutta Y: A novel two-component hybrid molecule regulates vascular morphogenesis of the Arabidopsis root. Genes Dev 2000, 14:2938-2943.

21. Rodriguez-Villalon A, Gujas B, Kang YH, Breda AS, Cattaneo P, Depuydt S, Hardtke CS: Molecular genetic framework for protophloem formation. Proc Natl Acad Sci U S A 2014, 111:11551-11556.

22. Schlereth A, Möller B, Liu W, Kientz M, Flipse J, Rademacher EH, Schmid M, Jürgens G, Weijers D: MONOPTEROS controls embryonic root initiation by regulating a mobile transcription factor. Nature 2010, 464:913-916.

23. De Rybel B, Möller B, Yoshida S, Grabowicz I, Barbier de Reuille P, Boeren S, Smith RS, Borst JW, Weijers D: A bHLH complex controls embryonic vascular tissue establishment and indeterminate growth in Arabidopsis. Dev Cell 2013, 24:426437.

24. Ohashi-Ito K, Bergmann DC: Regulation of the Arabidopsis root vascular initial population by LONESOME HIGHWAY. Development 2007, 134:2959-2968.

25. Ohashi-Ito K, Matsukawa M, Fukuda H: An atypical bHLH transcription factor regulates early xylem development downstream of auxin. Plant Cell Physiol 2013, 54:398-405. 
26. Ohashi-Ito K, Oguchi M, Kojima M, Sakakibara H, Fukuda H: Auxin-associated initiation of vascular cell differentiation by LONESOME HIGHWAY. Development 2013, 140:765-769.

27. Ohashi-Ito K, Saegusa M, Iwamoto K, Oda Y, Katayama H, Kojima M, Sakakibara H, Fukuda H: A bHLH complex activates vascular cell division via cytokinin action in root apical meristem. Curr Biol 2014, 24:2053-2058.

28. Kuroha T, Tokunaga H, Kojima M, Ueda N, Ishida T, Nagawa S, Fukuda H, Sugimoto K, Sakakibara H: Functional analyses of LONELY GUY cytokinin-activating enzymes reveal the importance of the direct activation pathway in Arabidopsis. Plant Cell 2009, 21:3152-3169.

29. Tokunaga H, Kojima M, Kuroha T, Ishida T, Sugimoto K, Kiba T, Sakakibara H: Arabidopsis lonely guy (LOG) multiple mutants reveal a central role of the LOGdependent pathway in cytokinin activation. Plant $J$ 2012, 69:355-365.

30. Ishida K, Yamashino T, Yokoyama A, Mizuno T: Three type-B response regulators, ARR1, ARR10 and ARR12, play essential but redundant roles in cytokinin signal transduction throughout the life cycle of Arabidopsis thaliana. Plant Cell Physiol 2008, 49:47-57.

31. Yokoyama A, Yamashino T, Amano Y, Tajima Y, Imamura A, Sakakibara H, Mizuno T:

Type-B ARR transcription factors, ARR10 and ARR12, are implicated in cytokinin-mediated regulation of protoxylem differentiation in roots of Arabidopsis thaliana. Plant Cell Physiol 2007, 48:84-96.

32. Hanzawa Y, Takahashi T, Komeda Y: ACL5: an Arabidopsis gene required for internodal elongation after flowering. Plant J 1997, 12:863-874.

33. Hanzawa Y, Takahashi T, Michael AJ, Burtin D, Long D, Pineiro M, Coupland G, Komeda Y: ACAULIS5, an Arabidopsis gene required for stem elongation, encodes a spermine synthase. EMBO J 2000, 19:4248-4256.

34. Clay NK, Nelson T: Arabidopsis thickvein mutation affects vein thickness and organ vascularization, and resides in a provascular cell-specific spermine synthase involved in vein definition and in polar auxin transport. Plant Physiol 2005, 138:767-777.

35. Imai A, Hanzawa Y, Komura M, Yamamoto KT, Komeda Y, Takahashi T: The dwarf phenotype of the Arabidopsis acl5 mutant is suppressed by a mutation in an upstream ORF of a bHLH gene. Development 2006, 133:3575-3585. 
36. Imai A, Komura M, Kawano E, Kuwashiro Y, Takahashi T: A semi-dominant mutation in the ribosomal protein L10 gene suppresses the dwarf phenotype of the acl5 mutant in Arabidopsis thaliana. Plant J 2008, 56:881-890.

37. Katayama H, Iwamoto K, Kariya Y, Asakawa T, Kan T, Fukuda H, Ohashi-Ito K: A negative feedback loop controlling bHLH complexes is involved in vascular cell division and differentiation in the root apical meristem. Curr Biol 2015, in press.

38. Vera-Sirera F, De Rybel B, Úrbez C, Kouklas E, Pesquera M, Álvarez-Mahecha JC, Minguet EG, Tuominen H, Carbonell J, Borst JW, Weijers D, Blázquez MA: A bHLH-based feedback loop restricts vascular cell proliferation in plants. Dev Cell 2015, in press.

39. Baima S, Forte V, Possenti M, Peñalosa A, Leoni G, Salvi S, Felici B, Ruberti I, Morelli G: Negative feedback regulation of auxin signaling by ATHB8/ACL5-BUD2 transcription module. Mol Plant 2014, 7:1006-1025.

40. Milhinhos A, Prestele J, Bollhöner B, Matos A, Vera-Sirera F, Rambla JL, Ljung K, Carbonell J, Blázquez MA, Tuominen H, et al.: Thermospermine levels are controlled by an auxin-dependent feedback loop mechanism in Populus xylem. Plant Journal 2013, 75:685-698.

41. Donner TJ, Sherr I, Scarpella E: Regulation of preprocambial cell state acquisition by auxin signaling in Arabidopsis leaves. Development 2009, 136:3235-3246.

42. Ilegems M, Douet V, Meylan-Bettex M, Uyttewaal M, Brand L, Bowman JL, Stieger PA: Interplay of auxin, KANADI and Class III HD-ZIP transcription factors in vascular tissue formation. Development 2010, 137:975-984.

43. Carlsbecker A, Lee JY, Roberts CJ, Dettmer J, Lehesranta S, Zhou J, Lindgren O, Moreno-Risueno MA, Vatén A, Thitamadee S, et al.: Cell signalling by microRNA165/6 directs gene dose-dependent root cell fate. Nature 2010, 465:316321.

44. Hirakawa Y, Kondo Y, Fukuda H: TDIF peptide signaling regulates vascular stem cell proliferation via the WOX4 homeobox gene in Arabidopsis. Plant Cell 2010, 22:2618-2629.

45. Hirakawa Y, Shinohara H, Kondo Y, Inoue A, Nakanomyo I, Ogawa M, Sawa S, OhashiIto K, Matsubayashi Y, Fukuda H: Non-cell-autonomous control of vascular stem cell fate by a CLE peptide/receptor system. Proc Natl Acad Sci U S A 2008, 105:15208-15213. 
46. Fisher K, Turner S: PXY, a receptor-like kinase essential for maintaining polarity during plant vascular-tissue development. Curr Biol 2007, 17:1061-1066.

47. Etchells JP, Provost CM, Mishra L, Turner SR: WOX4 and WOX14 act downstream of the PXY receptor kinase to regulate plant vascular proliferation independently of any role in vascular organisation. Development 2013, 140:2224-2234.

48. Etchells JP, Turner SR: The PXY-CLE41 receptor ligand pair defines a multifunctional pathway that controls the rate and orientation of vascular cell division. Development 2010, 137:767-774.

49. Suer S, Agusti J, Sanchez P, Schwarz M, Greb T: WOX4 imparts auxin responsiveness to cambium cells in Arabidopsis. Plant Cell 2011, 23:3247-3259.

50. Matsumoto-Kitano M, Kusumoto T, Tarkowski P, Kinoshita-Tsujimura K, Vaclavikova K, Miyawaki K, Kakimoto T: Cytokinins are central regulators of cambial activity. Proceedings of the National Academy of Sciences of the United States of America 2008, 105:20027-20031.

51. Etchells JP, Provost CM, Turner SR: Plant vascular cell division is maintained by an interaction between PXY and ethylene signalling. PLoS Genet 2012, 8:e1002997.

52. Whittington AT, Vugrek O, Wei KJ, Hasenbein NG, Sugimoto K, Rashbrooke MC, Wasteneys GO: MOR1 is essential for organizing cortical microtubules in plants. Nature 2001, 411:610-613.

53. Bichet A, Desnos T, Turner S, Grandjean O, Höfte H: BOTERO1 is required for normal orientation of cortical microtubules and anisotropic cell expansion in Arabidopsis. Plant J 2001, 25:137-148.

54. Burk DH, Liu B, Zhong R, Morrison WH, Ye ZH: A katanin-like protein regulates normal cell wall biosynthesis and cell elongation. Plant Cell 2001, 13:807-827.

55. Bouquin T, Mattsson O, Naested H, Foster R, Mundy J: The Arabidopsis lue1 mutant defines a katanin p60 ortholog involved in hormonal control of microtubule orientation during cell growth. J Cell Sci 2003, 116:791-801.

56. Azimzadeh J, Nacry P, Christodoulidou A, Drevensek S, Camilleri C, Amiour N, Parcy F, Pastuglia M, Bouchez D: Arabidopsis TONNEAU1 proteins are essential for preprophase band formation and interact with centrin. Plant Cell 2008, 20:21462159.

57. Camilleri C, Azimzadeh J, Pastuglia M, Bellini C, Grandjean O, Bouchez D: The Arabidopsis TONNEAU2 gene encodes a putative novel protein phosphatase $2 \mathrm{~A}$ 
regulatory subunit essential for the control of the cortical cytoskeleton. Plant Cell 2002, 14:833-845.

58. McClinton RS, Sung ZR: Organization of cortical microtubules at the plasma membrane in Arabidopsis. Planta 1997, 201:252-260.

59. Traas J, Bellini C, Nacry P, Kronenberger J, Bouchez D, Caboche M: Normal Differentiation Patterns in Plants Lacking Microtubular Preprophase Bands. Nature 1995, 375:676-677.

60. Ambrose JC, Shoji T, Kotzer AM, Pighin JA, Wasteneys GO: The Arabidopsis CLASP gene encodes a microtubule-associated protein involved in cell expansion and division. Plant Cell 2007, 19:2763-2775.

61. Pietra S, Gustavsson A, Kiefer C, Kalmbach L, Hörstedt P, Ikeda Y, Stepanova AN, Alonso JM, Grebe M: Arabidopsis SABRE and CLASP interact to stabilize cell division plane orientation and planar polarity. Nat Commun 2013, 4:2779.

62. Müller S, Han S, Smith LG: Two kinesins are involved in the spatial control of cytokinesis in Arabidopsis thaliana. Curr Biol 2006, 16:888-894.

63. Walker KL, Müller S, Moss D, Ehrhardt DW, Smith LG: Arabidopsis TANGLED identifies the division plane throughout mitosis and cytokinesis. Curr Biol 2007, 17:1827-1836.

64. Xu XFM, Zhao Q, Rodrigo-Peiris T, Brkljacic J, He CS, Müller S, Meier I: RanGAP1 is a continuous marker of the Arabidopsis cell division plane. Proceedings of the National Academy of Sciences of the United States of America 2008, 105:1863718642.

65. Smith LG, Hake S, Sylvester AW: The tangled-1 mutation alters cell division orientations throughout maize leaf development without altering leaf shape. Development 1996, 122:481-489.

66. Wu SZ, Bezanilla M: Myosin VIII associates with microtubule ends and together with actin plays a role in guiding plant cell division. Elife 2014, 3.

67. Mineyuki Y: The preprophase band of microtubules: Its function as a cytokinetic apparatus in higher plants. International Review of Cytology - a Survey of Cell Biology, Vol 187 1999, 187:1-49.

68. Lindeboom JJ, Nakamura M, Hibbel A, Shundyak K, Gutierrez R, Ketelaar T, Emons AM, Mulder BM, Kirik V, Ehrhardt DW: A mechanism for reorientation of cortical microtubule arrays driven by microtubule severing. Science 2013, 342:1245533. 
69. Kirik A, Ehrhardt DW, Kirik V: TONNEAU2/FASS regulates the geometry of microtubule nucleation and cortical array organization in interphase Arabidopsis cells. Plant Cell 2012, 24:1158-1170.

70. Chen X, Grandont L, Li H, Hauschild R, Paque S, Abuzeineh A, Rakusová H, Benkova E, Perrot-Rechenmann C, Friml J: Inhibition of cell expansion by rapid ABP1mediated auxin effect on microtubules. Nature 2014, 516:90-93.

71. Vineyard L, Elliott A, Dhingra S, Lucas JR, Shaw SL: Progressive transverse microtubule array organization in hormone-induced Arabidopsis hypocotyl cells. Plant Cell 2013, 25:662-676.

72. Lintilhac PM, Vesecky TB: Mechanical-Stress and Cell-Wall Orientation in Plants .2. The Application of Controlled Directional Stress to Growing Plants - with a Discussion on the Nature of the Wound Reaction. American Journal of Botany 1981, 68: $1222-1230$.

73. Hush JM, Hawes CR, Overall RL: Interphase Microtubule Reorientation Predicts a New Cell Polarity in Wounded Pea Roots. Journal of Cell Science 1990, 96:47-61. 74. Hardham AR, Mccully ME: Reprogramming of Cells Following Wounding in Pea (Pisum-Sativum-L) Roots .1. Cell-Division and Differentiation of New Vascular Elements. Protoplasma 1982, 112:143-151.

75. Hamant O, Heisler MG, Jönsson H, Krupinski P, Uyttewaal M, Bokov P, Corson F, Sahlin P, Boudaoud A, Meyerowitz EM, et al.: Developmental Patterning by Mechanical Signals in Arabidopsis. Science 2008, 322:1650-1655.

76. Van Damme D, De Rybel B, Gudesblat G, Demidov D, Grunewald W, De Smet I, Houben A, Beeckman T, Russinova E: Arabidopsis alpha Aurora kinases function in formative cell division plane orientation. Plant Cell 2011, 23:4013-4024.

77. Griffith ME, Mayer U, Capron A, Ngo QA, Surendrarao A, McClinton R, Jürgens G, Sundaresan V: The TORMOZ gene encodes a nucleolar protein required for regulated division planes and embryo development in Arabidopsis. Plant Cell 2007, 19:2246-2263.

78. Dong J, MacAlister CA, Bergmann DC: BASL controls asymmetric cell division in Arabidopsis. Cell 2009, 137:1320-1330.

79. Zhang Y, Wang P, Shao W, Zhu JK, Dong J: The BASL polarity protein controls a MAPK signaling feedback loop in asymmetric cell division. Dev Cell 2015, 33:136-149. 


\section{Highlighted references:}

- • [3] The TMO5-LHW module directly induces expression of LOG4, a rate-limiting enzyme in CK biosynthesis, linking auxin and cytokinin in the control of periclinal cell division in vascular tissues.

- - [21] The authors describe opposing activities of CLE45 and OPS dependent signals in sieve element precursors for the proper timing of protophloem specification and the progression of its differentiation.

- • [27] The T5L1-LHW transcription factor dimer establishes xylem precursor cells as a signal center and thus promotes procambial cell proliferation via cytokinin response.

- [39] This work describes the feedback regulation between auxin, the HD-ZIPIII family transcription factor ATHB8 and the thermospermine synthase genes ACL5 and BUD2.

- • [47] The authors show that WOX4 and WOX14, two transcription factors acting downstream of TDIF-PXY, act redundantly in controlling proliferation in the procambial cells of the stem.

- • [68] KATANIN-mediated severing at microtubule crossover sites is regulated by blue light and functions to reorient the microtubule array.

- [70] The authors describe that application of exogenous auxin on elongating cells results in microtubule reorientation from transverse to longitudinal.

- [71] Hormonal treatment of hyopcotyl cells with auxin and gibberellic acid is shown to synchronously induce reorientation of the microtubule array 